\title{
Evolution of Thermal and Mechanical Properties of Nitinol Wire as a Function of Ageing Treatment Conditions
}

\author{
Zifan Wang ${ }^{\text {a }}$, Joris Everaerts ${ }^{a}$, Enrico Salvati ${ }^{a}$, Alexander M. Korsunsky ${ }^{\text {a }}$ * \\ a Department of Engineering Science, University of Oxford, Parks Road, Oxford, OX1 3PJ, U.K.
}

\begin{abstract}
${ }^{*}$ Corresponding author. E-mail address: alexander.korsunsky@eng.ox.ac.uk (A. M. Korsunsky)
\end{abstract}
Keywords: NiTi shape memory alloys, Ageing, EBSD, DSC, JMA equation, Superelasticity.

\begin{abstract}
As-received and cold-worked 55Ni-45Ti wt\% Nitinol wire samples were subjected to various ageing treatments. Experiments show that the properties of as-received Nitinol, including microstructure, critical temperatures in thermally induced phase transformation, and salient values of stresses/strains in mechanically induced phase transformation, change significantly after ageing process at $773 \mathrm{~K}$ for different durations ranging from 10 minutes to 5 hours. EBSD/BSE results show a large increase in $\mathrm{Ni}_{4} \mathrm{Ti}_{3}$ precipitate volume fraction, while grain growth is negligible. DSC results show that as-received material exhibits little to no phase transformation during heating-cooling cycling at $5 \mathrm{~K} / \mathrm{min}$, while various ageing durations lead to the emergence of phase transformation that occur at different critical temperatures. A mathematical model is proposed to predict the dependence of transformation temperatures on the ageing time. Tensile loading experiment conducted using a test rig equipped with a heater revealed mechanically induced phase transformation and allowed quantifying the evolution of critical stresses and strains.
\end{abstract}

\section{Introduction}

Shape memory alloys (SMAs) belong to a class of shape memory materials (SMMs), which have the ability to "memorize" and recover their previous form through reversible solid-state phase transformation [1]. Among SMAs, NiTi binary alloys, also known as Nitinol, have been widely investigated due to their superior engineering properties, namely Shape Memory Effect (SME) and Superelasticity (SE). Both SME and SE are related to the transformation between Austenite (B2 Cubic) and Martensite (B19' Monoclinic), with an intermediate R-phase (Trigonal). Phase transformation can be induced thermally, by heating/cooling within a certain temperature range, or mechanically, by loading/unloading in some temperature regimes. The thermally induced phase transformation can be investigated using differential scanning calorimetry (DSC) [2]. Critical temperatures, such as $R_{\mathrm{s}}, R_{\mathrm{f}}$, $M_{\mathrm{s}}, M_{\mathrm{f}}, R_{\mathrm{s}}{ }^{\prime}, R_{\mathrm{f}}{ }^{\prime}, A_{\mathrm{s}}, A_{\mathrm{f}}$ can be determined by processing the DSC heating and cooling curves [3]. On the other hand, the mechanically induced phase transformation can be characterized using tension/compression tests conducted at temperatures between $A_{\mathrm{f}}$ and $\mathrm{T}_{\mathrm{d}}$ (the highest temperature for stress-induced martensite transformation). A stress plateau due to the austenite to martensite transformation becomes apparent in these tests [4].

The phase transformation phenomena outlined above underlie the ultimate engineering performance of NiTi shape memory alloy, as they determine the temperature and stress values for material to use in applications.

Heat treatment exerts significant impact on the phase transformation behavior of shape memory alloy. Heat treatment can be classified into annealing and ageing. The annealing temperature is much higher than ageing, usually above $873 \mathrm{~K}$ and up to $1273 \mathrm{~K}$ for Nitinol. NiTi alloys recrystallize during solution annealing, grains nucleate and grow, thus annealing is used at initial stage in fabrication. The ageing treatment is beneficial for the formation of precipitate phases [5]. Conducted between $573 \mathrm{~K}$ to $873 \mathrm{~K}$ for varying durations, the ageing process produces precipitates of different intermetallic compounds, including $\mathrm{Ni}_{4} \mathrm{Ti}_{3}, \mathrm{Ni}_{3} \mathrm{Ti}_{2}, \mathrm{Ni}_{3} \mathrm{Ti}$, etc. [6]. It is clear that the formation of these precipitates 
to a large extent controls the phase transformation behavior in NiTi shape memory alloy through various interaction mechanisms, e.g. through changing the internal stress state and local $\mathrm{Ni}$ concentration in the parent phase [7].

The effect of heat treatment on NiTi phase transformation process has been studied extensively. Losertova et al. studied the microstructure evolution of NiTi alloys subjected to ageing treatment of given duration as a function of temperature [8]. The transformation behavior and mechanical properties of NiTi alloys processed at various temperatures and time were examined in $[9,10,11]$. The formation of $\mathrm{Ni}_{4} \mathrm{Ti}_{3}$ precipitates after various heat treatments was discussed in $[12,13,14]$, and was proved to be the decisive factor in controlling the phase transformation response. Although the aforementioned studies have comprehensively discussed the phase transformation behavior and mechanical properties trends in NiTi alloys subjected to various heat treatment methods, these studies were mostly qualitative, leaving a knowledge gap in the quantitative analysis of these results. Most up-to-date published studies lack in-depth analysis and the establishment of analytical or empirical models. These restricts the application of research conclusions to engineering tasks, since the conditions of each experiment are unique, and the observations are not readily transferable. Therefore, it is necessary to propose models that can describe and predict the trends in the phase transformation behavior and mechanical properties of NiTi shape memory alloys after various heat treatment processes. Two parameters of NiTi alloy behavior are of critical importance in engineering applications, namely, the austenite finish temperature $\left(A_{\mathrm{f}}\right)$, and the plateau stress $\left(\sigma_{\mathrm{M}}\right)$. Above $A_{\mathrm{f}}, \mathrm{NiTi}$ alloy is fully austenitic at zero stress, so that the alloy can exhibit the most complete SE behavior under applied stress. $\sigma_{M}$ is the stress above which the austenite gradually converts into martensite, as the stress continues to rise. Therefore, $\sigma_{M}$ is the stress at which the material begins the large and recoverable deformation, up to the strain value of $5 \%$ to $10 \%$. Being able to customize the values of these two salient parameters would guide manufacturers to produce the most suitable NiTi shape memory alloys for different applications.

In the present study, both thermally and mechanically induced phase transformation studies were carried out on NiTi alloy with a fixed element ratio. The values of critical temperatures $\left(R_{\mathrm{s}}, R_{\mathrm{f}}, M_{\mathrm{s}}\right.$, $\left.M_{\mathrm{f}}, R_{\mathrm{s}}{ }^{\prime}, R_{\mathrm{f}}{ }^{\prime}, A_{\mathrm{s}}, A_{\mathrm{f}}\right)$ and salient stresses $\left(\sigma_{\mathrm{M}}, \sigma_{\mathrm{UP}}, \sigma_{\mathrm{LP}}\right)$ were extracted from thermal and mechanical experimental data using widely accepted methods [3]. The ultimate objective of this study is to establish a general model that can predict the dependence of the critical temperatures and stresses in NiTi alloy as a function of composition and heat treatment processing history. Therefore, the experimental results from other studies were used in addition to current findings in order to determine the model parameters. Electron Backscatter Diffraction (EBSD) and backscatter electron (BSE) images of the sample cross section were collected to determine the grain structure and precipitate evolution during heat treatment. A model is proposed that establishes the mathematical relationship between the volume fraction of precipitate, the Nickel:Titanium composition ratio, the temperature and duration of heat treatment, and the values of critical temperatures in the thermally induced phase transformation process. The outcome of this study provides guidance for heat treatment schedules to achieve the desired thermal-mechanical properties of NiTi shape memory alloy, thus saving labour and resources.

\section{Experimental Methodology}

A commercially available reel of pure binary NiTi wire (Goodfellow, Ni55/Ti45) of $0.8 \mathrm{~mm}$ diameter was used in the present study, the composition of which was verified by EDS. As-received samples were aged at 773K for several durations, namely, 10, 20, 30, 40, 50 minutes, and 1, 2, 3, 4, 5 hours. Together with the as-received sample, all aged samples were subjected to testing using DSC, tensile test, and EBSD/BSE mapping and imaging.

The thermally induced phase transformation characteristics were determined with a modulated TA DSC Q2000 in the wide temperature range between $183 \mathrm{~K}$ and $473 \mathrm{~K}$ to cover the complete transformation process. Samples for DSC tests were first cut into bars 2-3mm in length, aged and immediately quenched in cold water. In the DSC tests, the samples were first cooled down to $183 \mathrm{~K}$ and held for 5 minutes to stabilize, then heated to $473 \mathrm{~K}$, held isothermally for 2 minutes, and cooled 
again to $183 \mathrm{~K}$. The ramp rates for heating/cooling were both $5 \mathrm{~K} / \mathrm{min}$. Two cycles were conducted at each sample to eliminate random error.

The mechanically induced phase transformation experiments were carried out on Deben MicroTest $600 \mathrm{~N}$ tensile rig, see Fig.1. The samples were $30 \mathrm{~mm}$ in gauge length. A copper heating stage was used to keep the samples at a constant temperature. For deformation experiments, the temperature value of $323 \mathrm{~K}$ was set, approximately $20 \mathrm{~K}$ higher than $A_{\mathrm{f}}$, to enable complete recovery in SE behavior. A constant strain rate of $5 \times 10^{-4} \mathrm{~s}^{-1}$ was set, as recommended in the literature, to avoid self-heating effect during tensile loading. Two loading/unloading cycles were conducted on each sample to achieve a stable stress-strain response curve for subsequent data analysis.

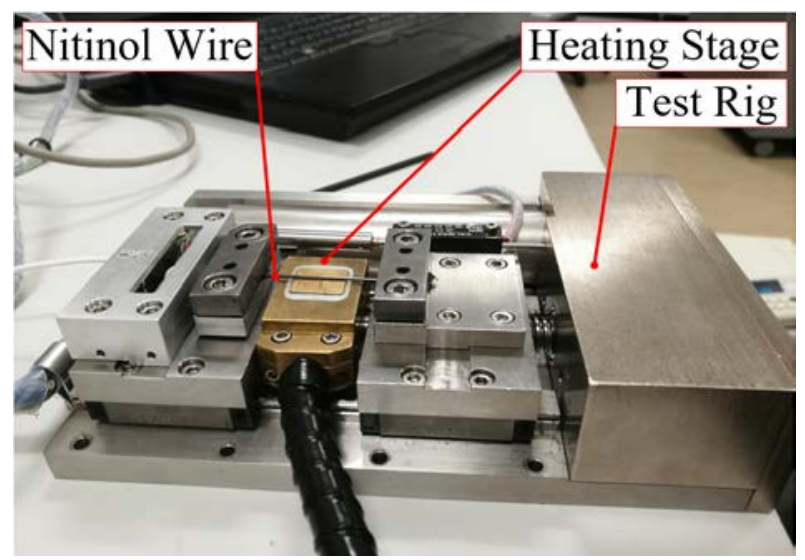

Figure.1 Layout of Deben tensile test rig for superelastic experiments.

To prepare for EBSD/BSE mapping and imaging experiments, the samples were embedded in an epoxy resin base, see Fig. 2 as an example. Only sample cross sections were exposed, $0.5024 \mathrm{~mm}^{2}$ each. The samples within the mount were mechanically ground step by step, down to 1200 grit $\mathrm{SiC}$ paper, followed by polishing using $9 \mu \mathrm{m}, 3 \mu \mathrm{m}$, to $1 \mu \mathrm{m}$ diamond suspension. The Buehler PoliMat 2 electropolishing device was used at the final stage, with an electrolyte containing $80 \%$ methanol and $20 \%$ sulfuric acid (95\% concentration) [15]. SEM analysis shows that $\sim 25 \mu \mathrm{m}$ of material was removed by electropolishing in the direction normal to the surface. Kikuchi patterns were indexed by commercial software AZtec from Oxford Instruments.

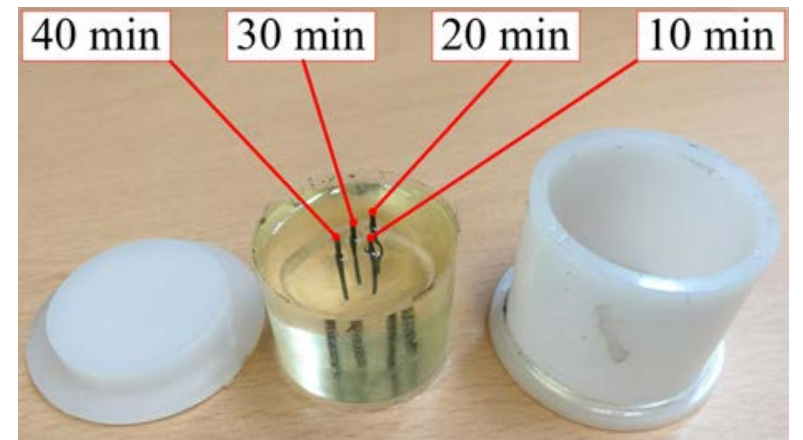

Figure.2 Samples of various ageing durations embedded in epoxy resin base that was cast using white plastic mould.

\section{Results and Discussion}

\subsection{EBSD and BSE}

EBSD patterns of the as-received and aged samples are shown in Fig.3. Grain size analysis was conducted on both patterns, which indicates that the average grain size (diameter) is approximately 334nm in Fig.3 (a) and 399nm in Fig.3 (b). This confirms that grain growth was very limited during ageing, in agreement with $[16,18]$. In this research the effect of ageing temperature on grain growth was studied, and it was found that hardly any growth occurs below $823 \mathrm{~K}$. Obvious change in grain 
size can be achieved by annealing at temperatures of $973 \mathrm{~K}$ or higher. The Euler colour distribution between and within grains in Fig.3(a) indicates the nature of lattice orientation variation within the sample. In contrast, the colour distribution within grains in Fig.3(b) appears more uniform, without a sudden change in color within a grain or at grain boundaries. Therefore, in terms of crystallinity, the samples tend to be more amorphous before ageing treatment and recrystallize slightly after.

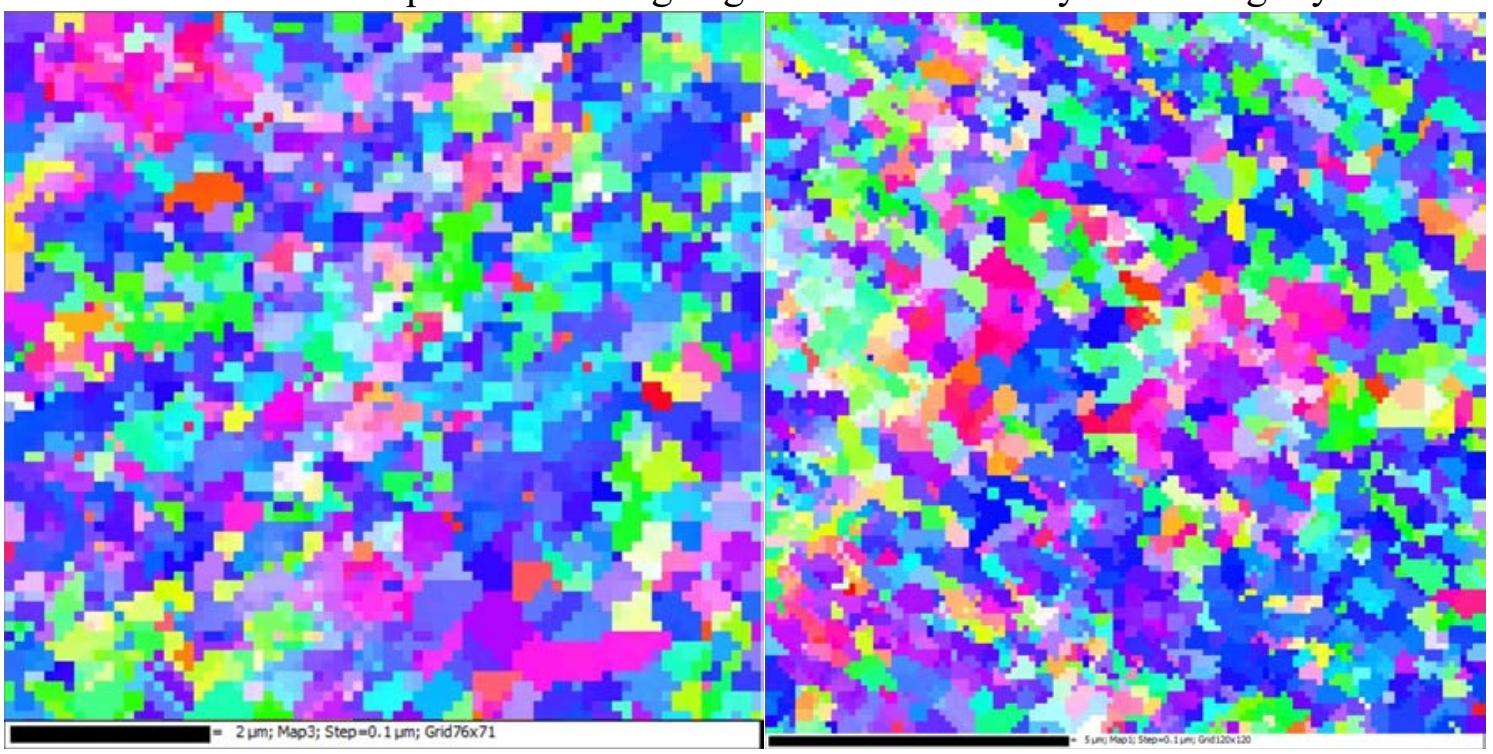

(a)

(b)

Figure. 3 EBSD pattern of (a)as-received (b)5 hours' aged NiTi shape memory alloy, the black bars represent the scales $(2 \mu \mathrm{m}$ and $5 \mu \mathrm{m}$, respectively).

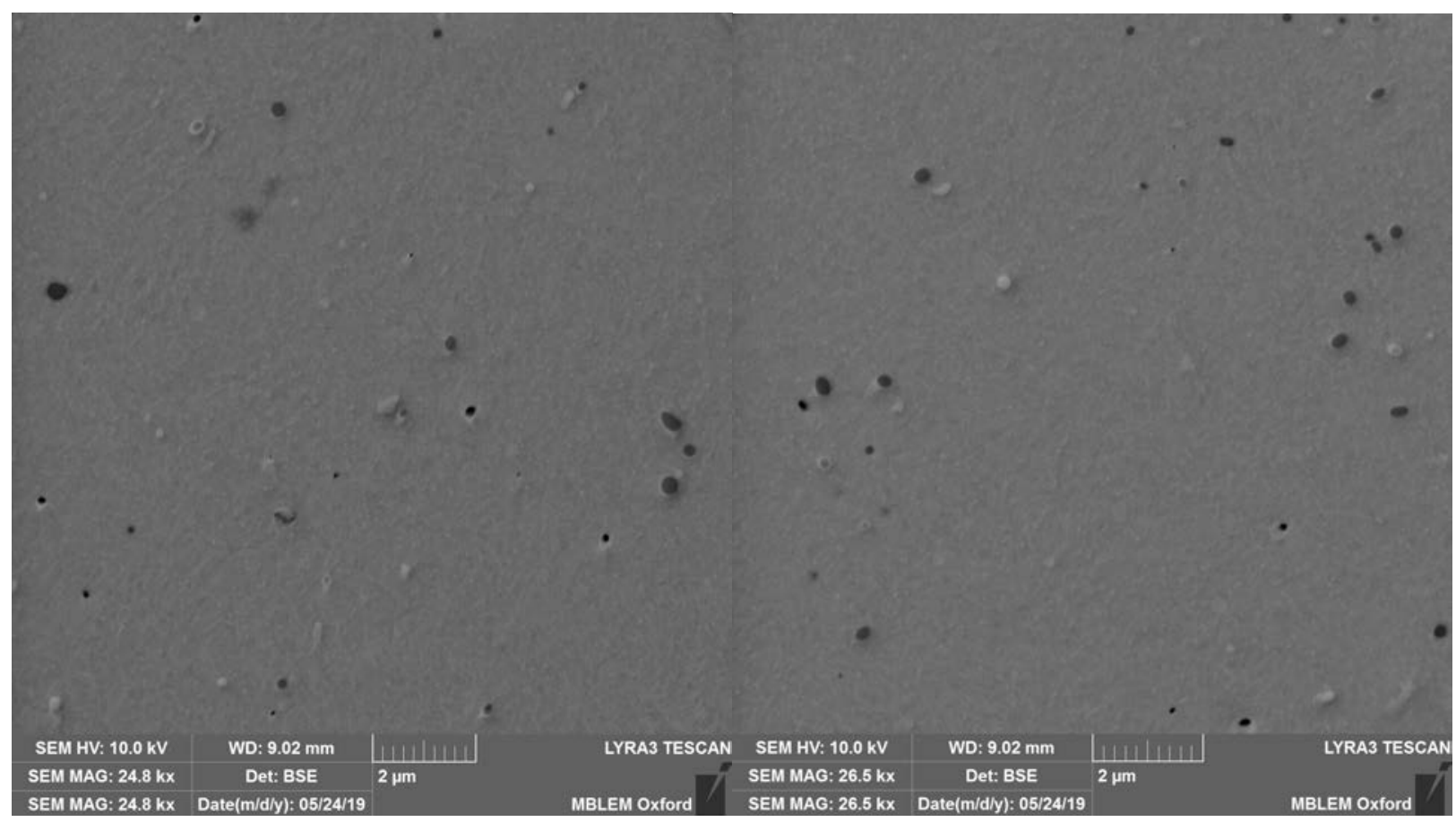

(a)

(b) 


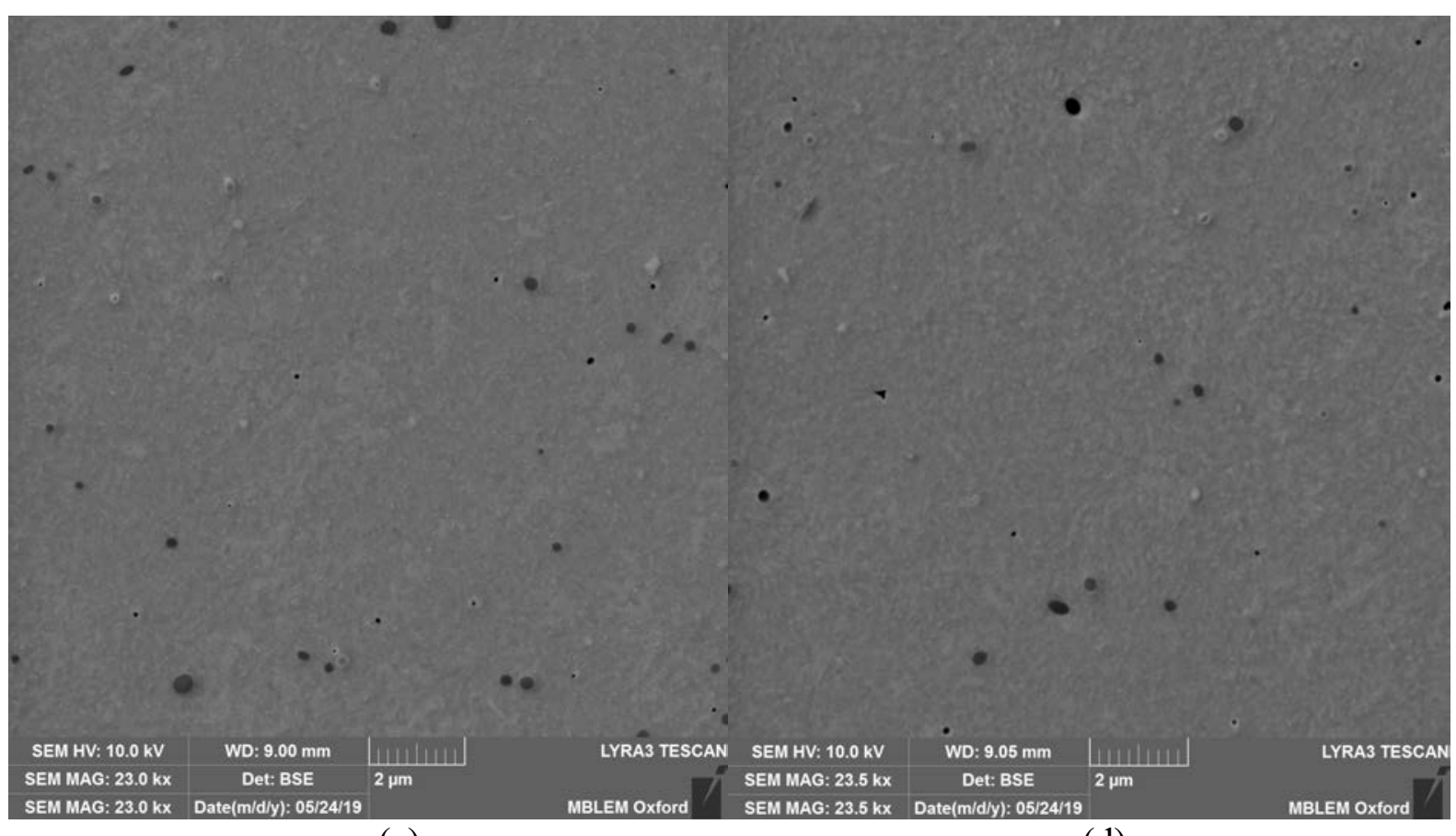

(c)

(d)

Figure.4 BSE images of sample surface with ageing durations of (a) 1 hour, (b) 2 hours, (c) 3 hours,

(d) 4 hours.

BSE images of sample cross section surfaces are shown in Fig.4. Compared with SEM imaging using secondary electron (SE) detector that is particularly sensitive to surface topography, the use of BSE detector reveals more clearly the sample microstructural features, such as grain boundaries, precipitates, and different phases. Sample electropolishing resulted in the appearance of black dots that may represent surface deposition, $\mathrm{Ni}_{2} \mathrm{Ti}_{4} \mathrm{O}$ oxide particles [12], or preferential material removal associated with internal crystal defects. Grain boundaries cannot be clearly distinguished in the images. The $\mathrm{Ni}_{4} \mathrm{Ti}_{3}$ precipitate phase nucleates and grows within the parent phase. A significant increase of lighter appearing precipitates against grey background (parent phase) can be observed in the image of 1 hours' aged sample to the image of 3 hours' aged sample. This finding agrees with the reported results of earlier research [17].

Thus, both EBSD and BSE results confirm negligible grain growth after ageing treatment at $773 \mathrm{~K}$ for 5 hours, however, the volume fraction of $\mathrm{Ni}_{4} \mathrm{Ti}_{3}$ precipitate exhibits a large increase. Previous studies also reported that heat treatment has no significant effect on the volume fraction of martensite/austenite parent phase ( $773 \mathrm{~K}$ for 1 hour) [18]. Therefore, a conclusion can be drawn that during ageing treatment below $823 \mathrm{~K}$, the formation of $\mathrm{Ni}_{4} \mathrm{Ti}_{3}$ precipitate dominates the microstructural evolution in binary NiTi shape memory alloy, while the change in the martensite/austenite phase volume fraction and grain growth can be neglected.

\subsection{Thermally Induced Phase Transformation}

The thermally induced phase transformation behavior monitored by DSC is shown in Fig.5 for samples subjected to varying ageing durations ranging from 10 mins to 5 hours. The phase transformation behavior for as-received sample was not detectable in DSC heating-cooling cycling. This confirms that as-received material prior to heat treatment after cold work does not undergo phase transformation.

In the DSC profiles, exothermic process corresponds to positive heat flow, thus upper curves indicate the cooling process. The temperature range of $-80^{\circ} \mathrm{C}$ to $90^{\circ} \mathrm{C}$ is shown in the graphs, as no transformation behavior was observed at higher temperatures between $90^{\circ} \mathrm{C}$ and $200^{\circ} \mathrm{C}$. It can be clearly seen from Fig.5 that the samples show two phase transformation features during cooling process. Since the average grain size is at the same magnitude as that of precipitate, it can be assumed that there is no precipitate-free region within grains. Therefore, the first peak in cooling process 
indicates austenite to R-phase transformation, while the second is R-phase to the martensite transformation [19]. The first peak in heating process indicates martensite to R-phase transformation, which can be observed in the samples with ageing duration of 30 mins or less. The two peaks converge to a single peak for the samples with ageing time longer than $40 \mathrm{mins}$, indicating that martensite directly transforms to austenite.

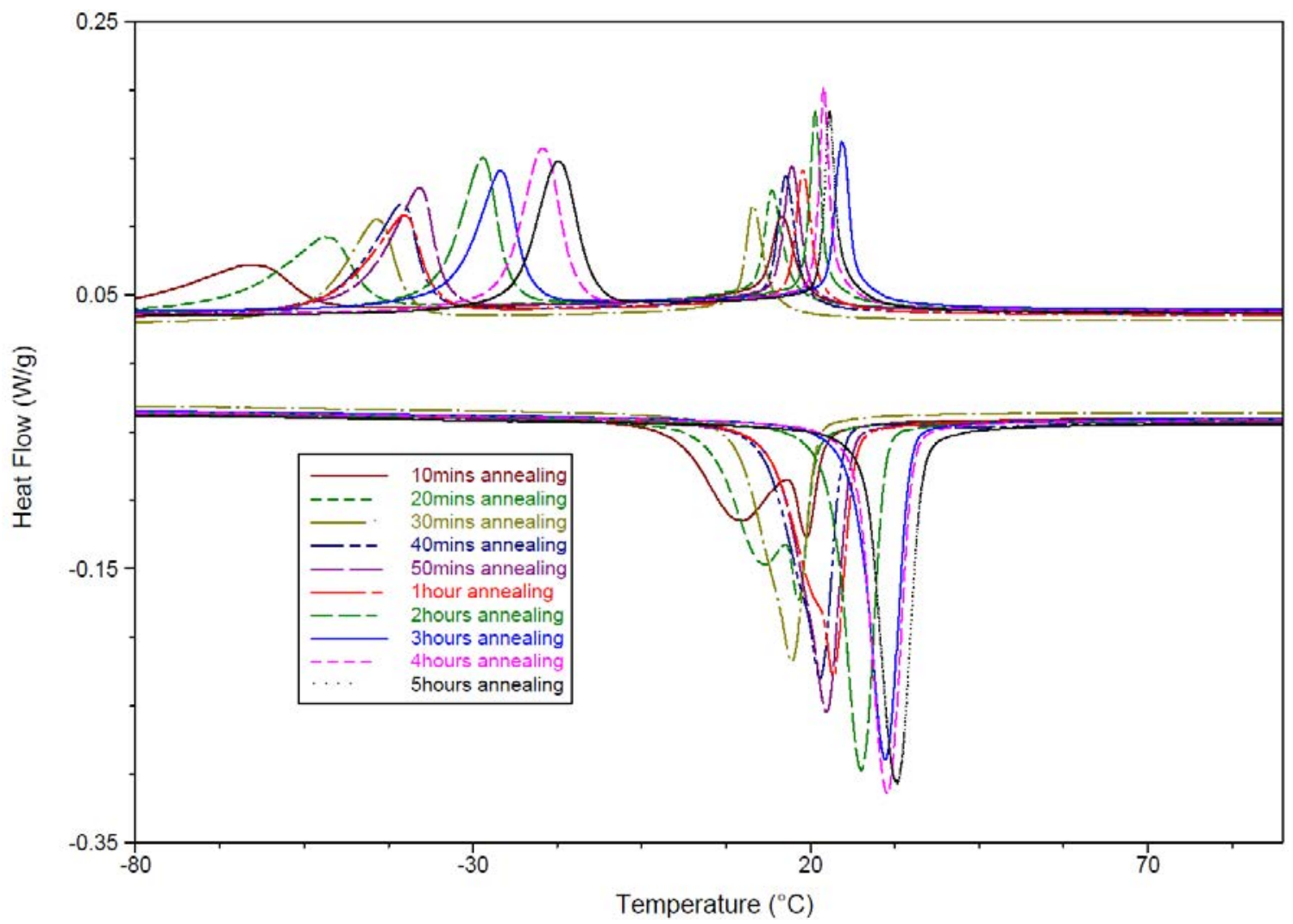

Figure.5 DSC cycles showing the evolution of phase transformation behavior.

It is apparent that the phase transformation peaks shift towards higher temperatures with the increasing of ageing time. For a single DSC heating-cooling cycle, the critical temperatures $\left(R_{\mathrm{S}}, R_{\mathrm{f}}\right.$, $\left.M_{\mathrm{s}}, M_{\mathrm{f}}, R_{\mathrm{s}}{ }^{\prime}, R_{\mathrm{f}}{ }^{\prime}, A_{\mathrm{s}}, A_{\mathrm{f}}\right)$ of thermally induced phase transformation process are determined according to ASTM standard, as shown in Fig.6. The evolution of critical temperatures of samples with varying ageing time are revealed in Fig.7.

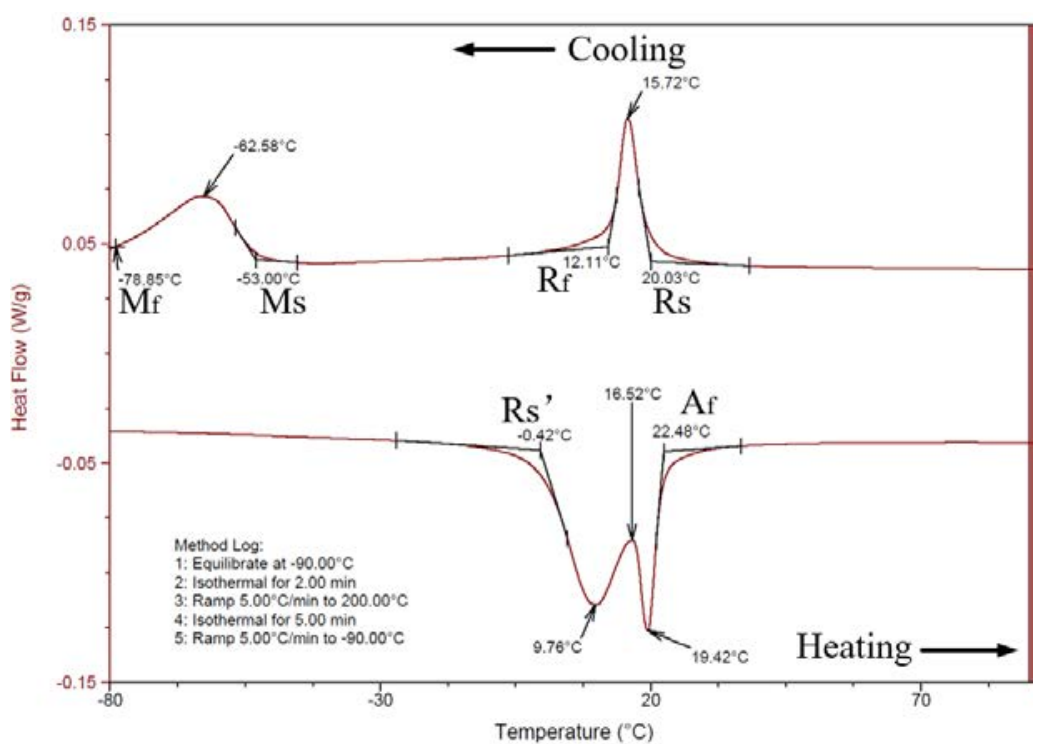

Figure. 6 The definition of critical temperatures, for the sample subjected to 10mins ageing. 


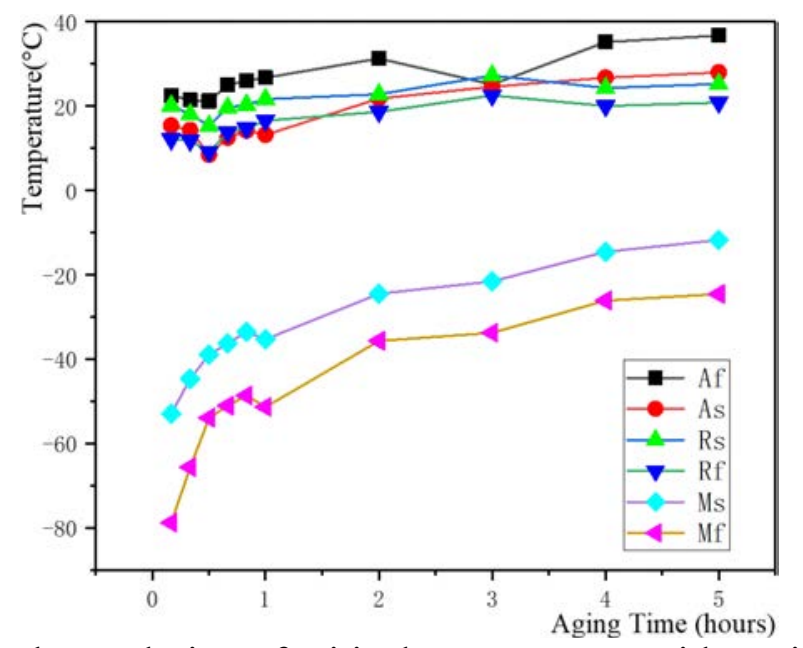

Figure.7 The evolution of critical temperatures with ageing time.

As concluded from the EBSD/BSE results, grain growth is negligible after ageing treatment at $773 \mathrm{~K}$, and the dominant microstructural change in the samples was the formation of $\mathrm{Ni}_{4} \mathrm{Ti}_{3}$ precipitate, which leads to the increase of volume fraction of $\mathrm{Ni}_{4} \mathrm{Ti}_{3}$ in parent phase.

\subsection{Theoretical description of thermally induced transformation}

Johnson-Mehl-Avrami (JMA) nucleation and growth kinetics is one of most useful models to evaluate the evolution of phase volume fractions during heating or cooling processing [20,21]. The non-isothermal phase-transformation kinetic model for the volume ratio of new phases can be described as [22]

$$
\left.f=\frac{V_{t}}{V_{\infty}}=\xi(T, t)=1-\exp \left\{-g \cdot \int_{0}^{t^{\prime}} I(T(t)) \cdot\left[\int_{t^{\prime}}^{t} G(T(\tau)) d \tau\right]^{n} d t\right)\right\} .
$$

Here, $V_{t}$ is the volume fraction of $\mathrm{Ni}_{4} \mathrm{Ti}_{3}$ precipitate at time $t, V_{\infty}$ is the ultimate volume fraction, $I(T(t))$ is the nucleation rate function, $T(t)$ is the function representing the dependence of temperature on time $t, G(T(\tau))$ is the growth rate function, and $g$ is the geometrical growth factor depending on the dimensionality of growth that happens in the volume, at surface, according to fractal dimension, etc.

Eq.(1) is the JMA equation that is used to describe the dependence on the process parameters, namely, the time $t$ and temperature $T$. It incorporates the effects of the two basic processes involved in the formation of the new phase: nucleation and growth. If it is assumed that $\mathrm{Ni}_{4} \mathrm{Ti}_{3}$ nucleates randomly at pre-existing sites, then the nucleation rate function is set to a constant $N_{0}$, so that Eq.(1) can be simplified into

$$
f=\xi(T, t)=1-\exp \left\{-g \cdot N_{0} \cdot\left[\int_{t^{\prime}}^{t} G(T(\tau)) d \tau\right]^{n}\right\},
$$

where $N_{0}$ is the nucleation rate constant.

The growth rate function can be given by the Arrhenius equation commonly used to describe the rate of chemical reaction and phase formation, and can be written as

$$
G(T(\tau))=A \cdot \exp \left(-\frac{Q}{R \cdot T(\tau)}\right)
$$

where the pre-exponential factor $A$, also known as the frequency factor, represents the frequency of collisions between atoms. The form of Eq. (2) can be further simplified by substituting Eq.(3), which can be written as

$$
f=1-\exp \left(-\eta^{n}\right)
$$

where

$$
\eta=k_{0} \cdot \int_{t^{\prime}}^{t} \exp \left(-\frac{Q}{R \cdot T(\tau)}\right) d \tau
$$

Note that $k_{0}$ has the same unit as the frequency factor $A\left(\mathrm{~s}^{-1}\right)$ that appears in the JMA model and the Arrhenius equation. The value of $k_{0}$ can be expressed as:

$$
k_{0}=A \cdot \sqrt[n]{g \cdot N_{0}},
$$


where $g$ is the geometrical growth factor, and $N_{0}$ is the number of nucleation sites. For samples obtained by different processing of NiTi alloy of the same composition, the value of $k_{0}$ is considered to be fixed.

In Eq.(4) and Eq.(5), $Q$ is the activation energy of phase-transformation. For binary NiTi alloy, the value of $Q$ is in the range $120-160 \mathrm{~kJ} \mathrm{~mol}^{-1}$ [23]. Therefore, in the present study, the mean value of $140 \mathrm{~kJ} \mathrm{~mol}^{-1}$ was taken. $n$ is the JMA index (or Avrami constant). Originally, $n$ was thought to have an integer value between 1 and 4, reflecting the nature of the transformation. Assuming site saturation, the value of $n$ is taken to be 1 , corresponding to a constant nucleation rate. $T$ is ageing temperature (in units of $\mathrm{K}$ ); $t$ is the ageing time (in units of min); $f$ is the volume ratio of the new phase $\left(\mathrm{Ni}_{4} \mathrm{Ti}_{3}\right.$ ), and $R$ is the gas constant $\left(8.314 \mathrm{~J} \mathrm{~mol}^{-1} \mathrm{~K}^{-1}\right)$.

If ageing treatment is considered to be an isothermal process, Eq.(5) can be rewritten as

$\eta=k_{0} \cdot \exp \left(-\frac{Q}{R \cdot T}\right) \cdot t$.

The thermodynamic equilibrium between two phases during binary NiTi alloy phase transformation in the presence of crystal defects can be expressed in the following way $[24,25,26]$ :

$\Delta G=\Delta H-T \cdot \Delta S+\Delta E_{e}+\Delta E_{i}$,

where $\Delta G=G_{1}-G_{2}$ is the change in free energy, $G_{1}$ and $G_{2}$ refer to Gibbs free energy curves for two phases in NiTi alloy, $\Delta H$ and $\Delta S$ are the changes in chemical enthalpy and entropy respectively, $T$ is the temperature, $\Delta E_{e}$ is the change in elastic strain energy and $\Delta E_{i}$ is the reversible work associated with the transformation. $\Delta E_{e}$ can be expressed as:

$$
\Delta E_{e}=-\frac{1}{2} \cdot \sigma_{i j}^{\mathrm{t}} \cdot \varepsilon_{i j}^{\mathrm{t}}-\sigma_{i j} \cdot \varepsilon_{i j}^{\mathrm{t}}-\sigma_{i j}^{\mathrm{d}} \cdot \varepsilon_{i j}^{\mathrm{t}},
$$

where $\sigma_{i j}, \sigma_{i j}^{\mathrm{d}}, \sigma_{i j}^{\mathrm{t}}$, are the nonhydrostatic external applied stress, the internal stress field due to the presence of precipitate and the internal stress field associated with the phase transformation respectively. $\varepsilon_{i j}^{t}$ is the transformation strain. Rearranging Eq.8 gives expression as:

$$
T=T_{0}+\left(\frac{\Delta E_{e}+\Delta E_{i}}{\Delta S}\right)
$$

where $T$ is the equilibrium temperature between two adjacent phases and $T_{0}=(\Delta H-\Delta G) / \Delta S$. The approach can be taken that when $T=\left(A_{\mathrm{s}}, A_{\mathrm{f}}, R_{\mathrm{s}}, R_{\mathrm{f}}, M_{\mathrm{s}}, M_{\mathrm{f}}\right)$ both the dissipative energy $\Delta E_{i}$ and reversible elastic stress $\sigma_{i j}$ can be neglected since nucleation energies and elastic stored energies are small at the beginning/end of the transformation. As external applied stress is absent, $\Delta E_{i}=0$ and $\sigma_{i j}^{t_{i j}}$ $=0$, following expression can be written:

$$
\left(A_{\mathrm{s}}, A_{\mathrm{f}}, R_{\mathrm{s}}, R_{\mathrm{f}}, M_{\mathrm{s}}, M_{\mathrm{f}}\right)=T_{0}+\frac{\Delta E_{e}}{\Delta S}=T_{0}+\frac{-\sigma_{i j}^{\mathrm{d}} \cdot \varepsilon_{i j}^{\mathrm{t}}}{\Delta S}
$$

where $\Delta E_{e}=-\sigma_{i j}^{\mathrm{d}} \mathrm{t}_{i j}^{\mathrm{t}}$ is the elastic strain energy induced by precipitates. Eq.11 is a local form of Clausius-Clapeyron equation [27], which shows that critical transformation temperatures are related to the internal stress field $\sigma_{i j}^{\mathrm{d}}$ induced by the $\mathrm{Ni}_{4} \mathrm{Ti}_{3}$ precipitate. It is obvious that the evolution of critical transformation temperatures will be proportional to the elastic strain energy and inversely proportional to the transformation entropy. For a single phase transformation process, e.g. austenite to R-phase or R-phase to martensite, the transformation entropy $\Delta S$ and elastic strain $\varepsilon_{i j}^{t}$ are constants. As is mentioned, $\mathrm{Ni}_{4} \mathrm{Ti}_{3}$ precipitate is assumed to nucleate at pre-determined sites, therefore the increase in precipitate volume ratio is due to the size growth. In [28], $\sigma_{i j}^{\mathrm{d}_{i j}}$ is simulated surrounding $\mathrm{Ni}_{4} \mathrm{Ti}_{3}$ precipitate. It might be assumed that $\sigma_{i j}^{\mathrm{d}}$ is directly proportional to precipitate size so that it can be written in the following form:

$$
\sigma_{i j}^{\mathrm{d}}=k^{\prime} \cdot f
$$

where $k^{\prime}$ refers to the scale factor (in units of $\mathrm{MPa}$ ). The following expression can be obtained by combining Eq.4, Eq.7, Eq.11, Eq.12:

$$
\left(A_{\mathrm{S}}, A_{\mathrm{f}}, R_{\mathrm{S}}, R_{\mathrm{f}}, M_{\mathrm{S}}, M_{\mathrm{f}}\right)=T_{0}+\frac{-k^{\prime} \cdot\left(1-\exp \left(-\left(k_{0} \cdot \exp \left(-\frac{Q}{R \cdot T}\right) \cdot t\right)^{n}\right)\right) \cdot \varepsilon_{i j}^{\mathrm{t}}}{\Delta S} .
$$

Eq.13 reveals the evolution of critical phase transformation temperatures with respect to aging time and temperature.

Influence of $\mathrm{Ni}$ concentration on the phase transformation temperatures has been studied in $[29,30]$. Ture Ni concentration $x_{\mathrm{Ni}}^{\mathrm{p}}$, , , C can be defined as: 


$$
x_{\mathrm{Ni}}^{p, O, C}=\frac{n_{\mathrm{Ni}}^{*}}{n_{\mathrm{Ni}}^{*}+n_{\mathrm{Ti}}^{*}},
$$

where $n_{\mathrm{Ni}}{ }^{*}$ and $n_{\mathrm{Ti}}{ }^{*}$ are numbers of $\mathrm{Ni}$ and Ti atoms in the NiTi alloy bulk. The shift in critical phase transformation temperatures associated with Ni concentration in binary NiTi shape memory alloy can be described by equation [29]:

$$
\left(A_{\mathrm{s}}{ }^{\prime}, A_{\mathrm{f}}{ }^{\prime}, R_{\mathrm{s}}{ }^{\prime}, R_{\mathrm{f}}{ }^{\prime}, M_{\mathrm{s}}{ }^{\prime}, M_{\mathrm{f}}{ }^{\prime}\right)=\left(A_{\mathrm{s}}, A_{\mathrm{f}}, R_{\mathrm{s}}, R_{\mathrm{f}}, M_{\mathrm{s}}, M_{\mathrm{f}}\right)+a_{1}+a_{2} \cdot x_{\mathrm{Ni}}^{p, O, C}+a_{3} \cdot a_{4}{ }^{x_{\mathrm{Ni}}^{p, O, C}}
$$

where $a_{\mathrm{i}}(\mathrm{i}=1,2,3,4)$ are the fitting parameters of experimental data, details of which refer to [29].

Substituting Eq.13 into Eq. 15 can give the following equation:

$$
\left(A_{\mathrm{s}}{ }^{\prime}, A_{\mathrm{f}}{ }^{\prime}, R_{\mathrm{s}}{ }^{\prime}, R_{\mathrm{f}}{ }^{\prime}, M_{\mathrm{S}}{ }^{\prime}, M_{\mathrm{f}}{ }^{\prime}\right)=\frac{-k^{\prime} \cdot\left(1-\exp \left(-\left(k_{0} \cdot \exp \left(-\frac{Q}{R \cdot T}\right) \cdot t\right)^{n}\right)\right) \cdot \varepsilon_{i j}^{\mathrm{t}}}{\Delta S}+T_{0}+a_{1}+a_{2} \cdot x_{\mathrm{Ni}}^{p, O, C}+a_{3} \cdot a_{4}{ }^{x_{\mathrm{Ni}}^{p, O, C}} \text {. }
$$

Once a NiTi shape memory alloy is fabricated, its Ni concentration is fixed, therefore the last four items in Eq.16 are constants. As aforementioned, for a particular phase transformation, e.g. austenite to R-phase or R-phase to martensite, the transformation entropy $\Delta S$ and elastic strain $\varepsilon_{i j}{ }_{i j}$ are constants. $k$ ' is a constant. $T_{0}$ is also a constant when the alloy is at an equilibrium temperature.

Considering all the above factors, Eq.16 can be simplified as:

$$
\left(A_{\mathrm{s}}, A_{\mathrm{f}}, R_{\mathrm{s}}, R_{\mathrm{f}}, M_{\mathrm{s}}, M_{\mathrm{f}}\right)_{\left(t, T, x_{\mathrm{Ni}}^{p, O, C}\right)}=k_{1} \cdot\left(1-\exp \left(-\left(k_{0} \cdot \exp \left(-\frac{Q}{R \cdot T}\right) \cdot t\right)^{n}\right)\right)+k_{2},
$$

where

$$
k_{1}=\frac{-k^{\prime} \cdot \varepsilon_{i j}^{\mathrm{t}}}{\Delta S}, \text { in units of Kelvin }(\mathrm{K})
$$
and

$$
k_{2}=T_{0}+a_{1}+a_{2} \cdot x_{\mathrm{Ni}}^{p, O, C}+a_{3} \cdot a_{4} x_{\mathrm{Ni}}^{p, O, C},
$$

and also has units of $\mathrm{K}$.

For both the start and finish temperatures of single-phase transformation process, i.e. $A_{\mathrm{s}}$ and $A_{\mathrm{f}}, R_{\mathrm{s}}$ and $R_{\mathrm{f}}, M_{\mathrm{s}}$ and $M_{\mathrm{f}}$, the value of $k_{1}$ can be assumed to be constant. In contrast, the value of $k_{2}$ varies due to the change in Gibbs free energy and parameters $a_{i}$ as a function of temperature. As is mentioned, the value of $k_{0}$ is fixed for samples obtained by different processing of NiTi alloy of the same composition.

Eq.17 gives the model proposed in the present study. It can be used to calculate the values of critical temperatures of NiTi alloy subjected to various ageing durations, temperatures and $\mathrm{Ni}$ concentration. The model is verified by fitting it to six critical phase transformation temperatures data from DSC experiments. In the proposed model, three parameters determine the ultimate mathematical expression, namely $k_{0}, k_{1}$, and $k_{2}$. These three parameters may vary accordingly for the calculation of different critical temperatures. The values of these parameters are determined through fitting the experiment data. The $\mathrm{R}^{2}$ value is used to find the best fit. Specific parameters for each critical temperature are shown in Table 1.

Table 1

Model parameters for each critical phase transformation temperature.

\begin{tabular}{ccccccc}
\hline Critical Temperature & $A_{\mathrm{S}}$ & $A_{\mathrm{f}}$ & $R_{\mathrm{S}}$ & $R_{\mathrm{f}}$ & $M_{\mathrm{s}}$ & $M_{\mathrm{f}}$ \\
\hline$k_{0}\left(\mathrm{~min}^{-1}\right)$ & $3 \times 10^{7}$ & $3 \times 10^{7}$ & $3 \times 10^{7}$ & $3 \times 10^{7}$ & $3 \times 10^{7}$ & $3 \times 10^{7}$ \\
$k_{1}(\mathrm{~K})$ & 19.21 & 19.21 & 12.96 & 12.96 & 50.02 & 50.02 \\
$k_{2}(\mathrm{~K})$ & 8.53 & 18.69 & 14.19 & 8.63 & -54.27 & -81.15 \\
\hline
\end{tabular}

For the critical temperatures given in Table 1, the experiment data and the theoretical curve from proposed model are illustrated in the same graph, as shown in Fig.8. Six graphs correspond to six critical phase transformation temperatures, respectively.

Regarding the prediction of $A_{\mathrm{f}}$, the proposed model shows good match, with the exception of the data from sample with 3 hours ageing. Judging from the other data points, this appears to be a random outlier, since such dramatic deviation is not observed in other plots. The first few experimental data 
for $A_{\mathrm{s}}$ seem to be freely distributed within a certain range of the order of $5^{\circ} \mathrm{K}$. This means that the ageing treatment may not affect the value of $A_{\mathrm{s}}$ within the first hour. Nevertheless, for the remaining experimental data the model shows good agreement.

The experimental data for $R_{\mathrm{s}}$ and $R_{\mathrm{f}}$ shows relatively significant fluctuating behavior. For instance, both data values at 3 hours are nearly $2.5^{\circ} \mathrm{K}$ higher than the model value, data values at 4 hours and 5 hours are about $1^{\circ} \mathrm{K}$ and $0.5^{\circ} \mathrm{K}$ lower than the model values, respectively. This phenomenon implies that the widths of austenite to R-phase transformation peaks hardly change with ageing time. Thermodynamics states that the change in Gibbs free energy is the driving force for phase transformation, and that to the first approximation the change in energy is proportional to the change of object temperature. Therefore, if the change in temperature remains the same, it means the energy required for phase transformation from austenite to R-phase may not change with ageing duration.

The experimental values of $M_{\mathrm{s}}$ and $M_{\mathrm{f}}$ are also matched well by the model curve.

The proposed model describes well the evolution trends of the critical phase transformation temperatures. Whether from the experiment data or from the model, the conclusion is drawn that these critical temperatures increase with the increasing ageing time, and finally converge to an upper limit. This "upper limit" prediction from the model coincides with the experimental results from other studies.

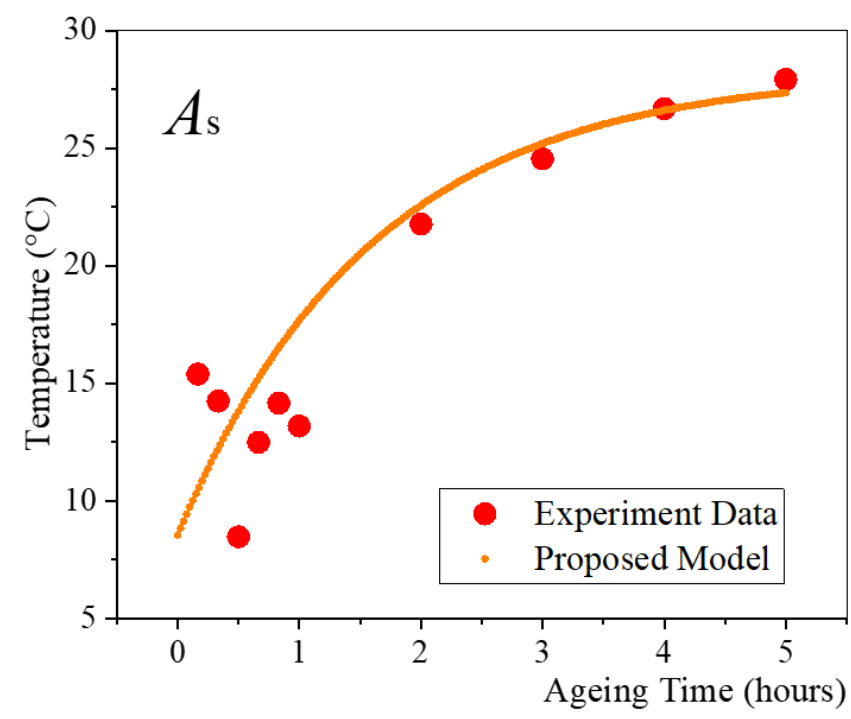

(a)

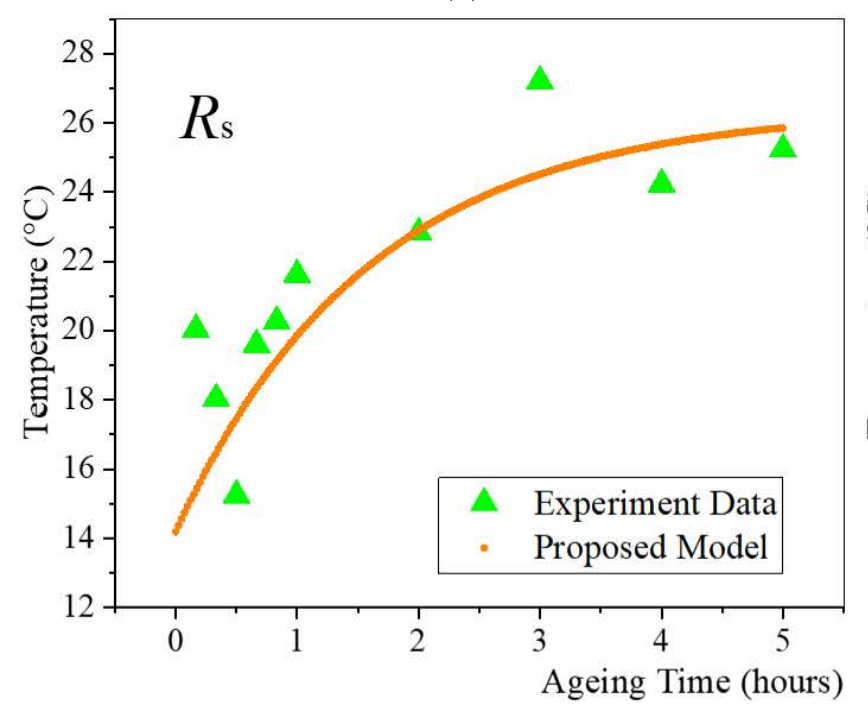

(c)

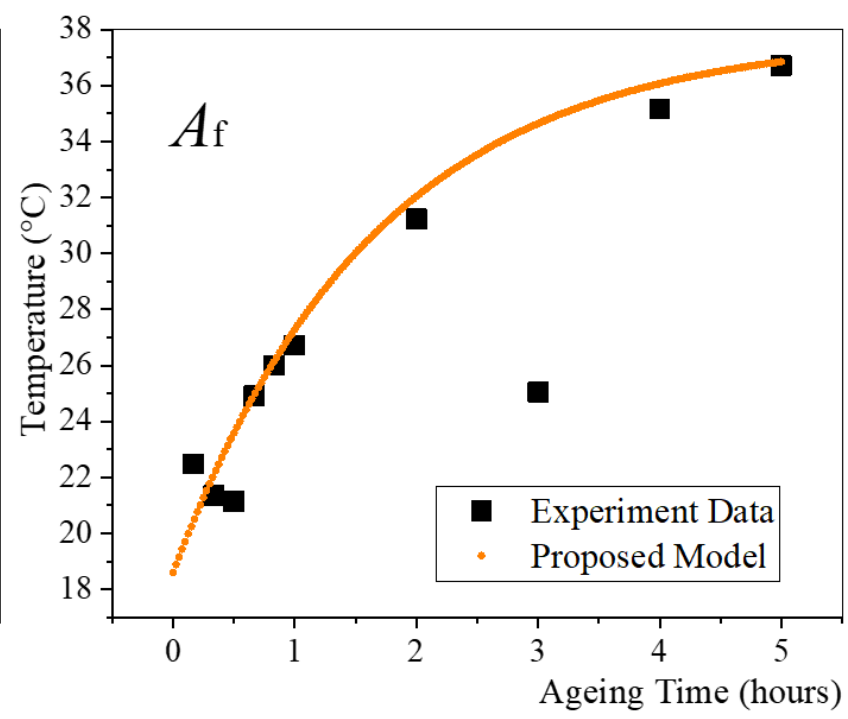

(b)

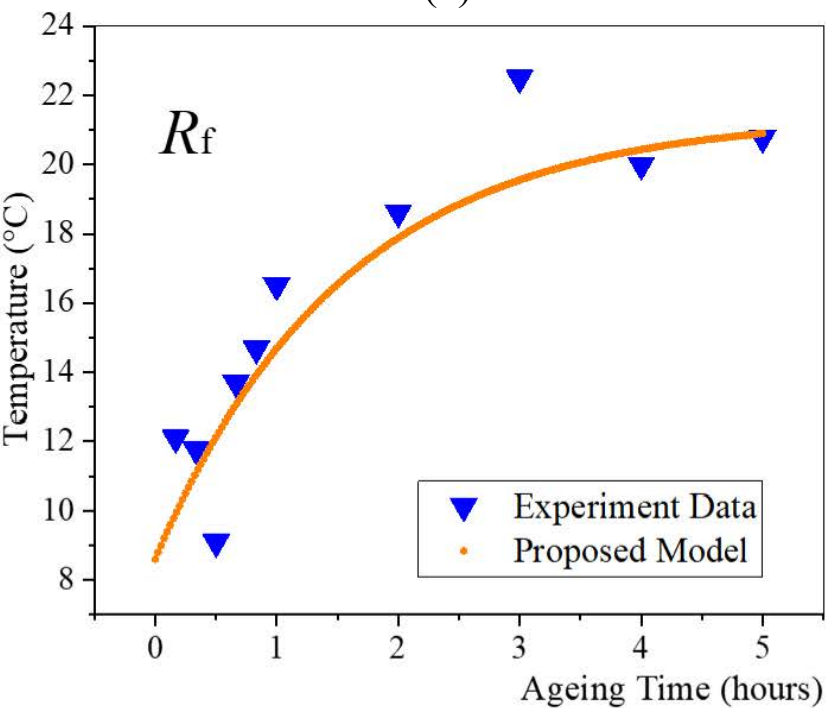

(d) 


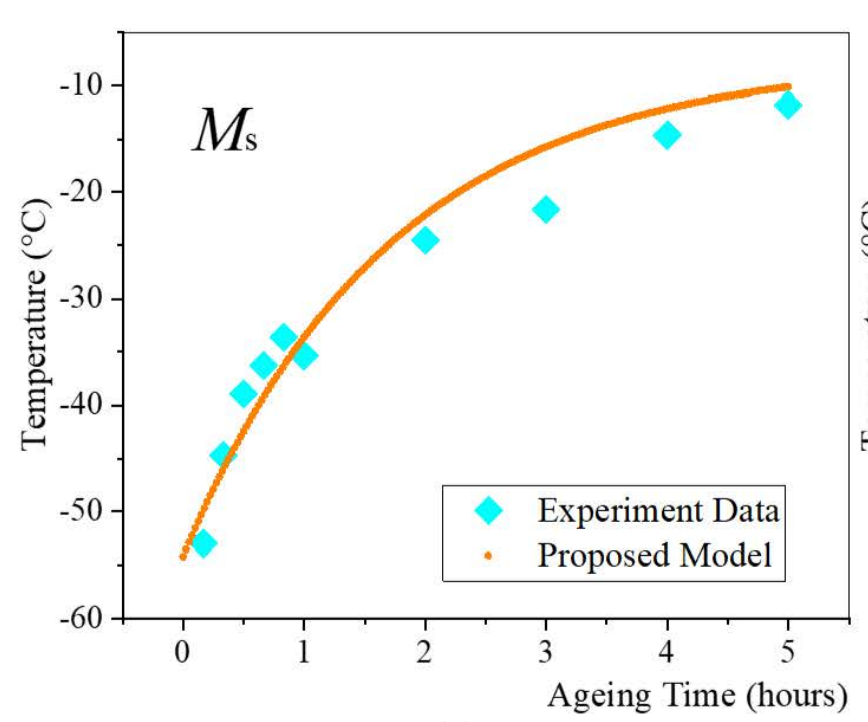

(e)

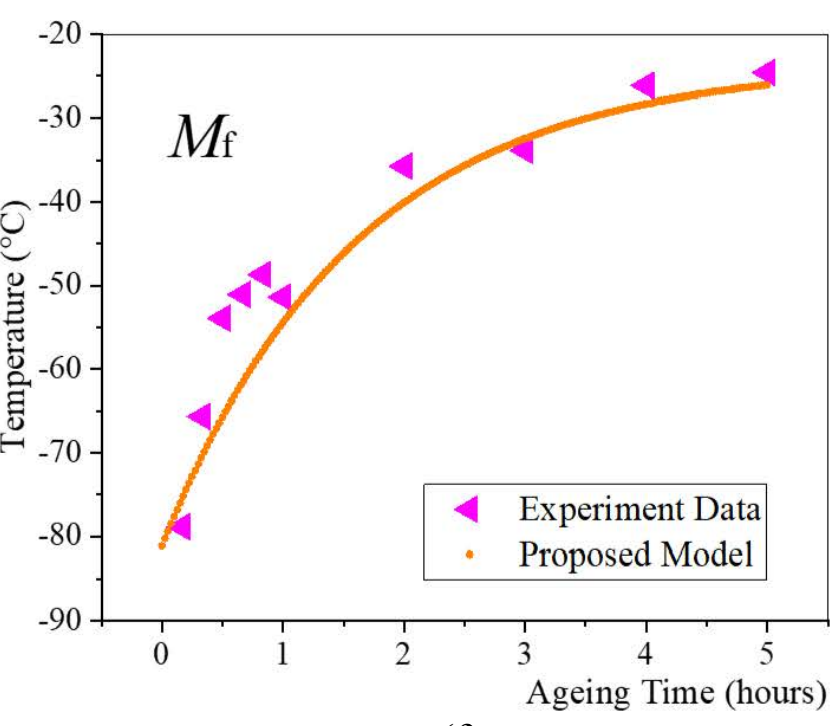

(f)

Figure.8 Comparison between experiment data and the proposed model, with abscissa being the ageing duration ranging from 0 to 5 hours, the ordinate is the critical temperatures, namely (a) $A_{\mathrm{s}}$, (b) $A_{\mathrm{f}},(\mathrm{c}) R_{\mathrm{s}},(\mathrm{d}) R_{\mathrm{f}},(\mathrm{e}) M_{\mathrm{s}},(\mathrm{f}) M_{\mathrm{f}}$, during thermally induced phase transformation process of binary NiTi alloy.

According to the thermodynamic and mathematical basis of the present model, the following conclusions can be drawn with respect to the model parameters:

(1) Whilst the number density of nucleation sites $N_{0}$ and the frequency factor $A$ may change due to the variation in the composition of binary NiTi alloy, the geometrical growth factor of precipitate $g$ remains unchanged. For NiTi alloys with the same composition, $N_{0}, A$ and $g$ are fixed, therefore, Eq.(6) shows that the value of $k_{0}$ is fixed. From the mathematical perspective, Eq.(17) shows that the larger the value of $k_{0}$, the steeper the curve, indicating the faster transformation rate and growth kinetics of $\mathrm{Ni}_{4} \mathrm{Ti}_{3}$ precipitates.

(2) For a particular phase transformation process, the entropy change $\Delta S$, the elastic strain $\varepsilon_{i j}^{\mathrm{t}}$, and the scale factor $k$ ' of volume ratio and internal stress field are fixed. For different phase transformation processes, the value of $\Delta S$ and $\varepsilon_{i j}^{t}$ may change. Therefore, Eq.(18) shows that the value of $k_{1}$ is fixed for the start and finish temperatures of a given phase transformation process, but it changes between different processes. From the mathematical perspective of Eq.(17), the value of $k_{1}$ determines the total variation of the critical temperatures due to ageing.

(3) The change in Gibbs free energy $\Delta G$ depends on temperature, though the values of chemical enthalpy and entropy remain the same for a particular phase transformation process. Therefore, the value of $T_{0}$ varies, resulting in different values of $k_{2}$ (see Eq.(19)) for different critical temperatures. From the mathematical perspective of Eq.(17), the value of $k_{2}$ determines the starting point of critical temperature evolution.

The three conclusions above are verified by observing the fitted parameters in Table 1, and the good match obtained between the model predictions and experimental data in Fig.8. 


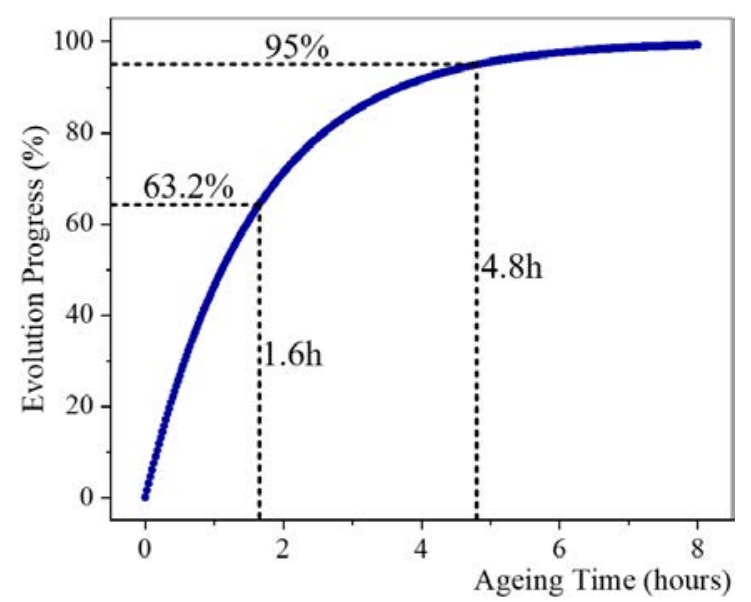

Figure.9 Percentage of completion of critical temperature evolution due to ageing treatment.

The evolution progress of critical temperatures is defined in the following expression, derived from Eq.(17):

$$
P=\left(1-\exp \left(-k_{0} \cdot \exp \left(-\frac{Q}{R \cdot T}\right) \cdot t\right)\right) \times 100 \%,
$$

where $P$ is the percentage of completion of evolution, and $t$ is the ageing time in units of minutes.

Substituting $\left(k_{0}, Q, R, T\right)$ in Eq.(20) with numerical values gives an exponential curve shown in Fig.9. The value of $P$ indicates how much the critical temperatures have evolved towards the upper limit. The characteristic time $t_{\mathrm{c}}$ of temperature evolution is found as:

$$
t_{\mathrm{c}}=\left(k_{0} \cdot \exp \left(-\frac{Q}{R \cdot T}\right)\right)^{-1} \approx 96 \mathrm{mins} \approx 1.6 \mathrm{hrs} .
$$

Eq.20 gives the result that:

$$
P=(1-\exp (-1)) \times 100 \% \approx 63.2 \%,
$$

i.e. the temperature evolution is about $2 / 3$ completed at characteristic time $t_{\mathrm{c}}$ of ageing treatment for NiTi alloy.

Similarly, approximately 4.8 hours of ageing results in $\sim 95 \%$ of completion of temperature evolution.

The characteristic time $t_{\mathrm{c}}$ may change due to different NiTi composition, since the value of $k_{0}$ is associated with intrinsic properties of materials.

Eq.(20) describes the evolution progress of all critical temperatures of binary NiTi alloy, and for alloys with the same composition and fabrication method, the characteristic time is fixed for all critical temperatures due to the fixed value of $k_{0}$.

The applications of the proposed model are versatile and beneficial. In the first instance, based on DSC data of a NiTi alloy subjected to ageing treatment, the proposed model can fit and predict the maximum values of critical temperatures of the alloy. In the second instance, the manufacturers of NiTi shape memory alloy material and components, phase transformation temperature customization can be achieved. For example, NiTi stents for blood vessels need to display phase transformation response as precisely defined temperatures. The current model can be used to provide guidance to identify the most suitable ageing treatment schedule. It is worth noting that for as-received binary NiTi alloys, the present model may not be applicable, since thermally induced phase transformation does not appear to occur in NiTi alloys without ageing treatment.

\subsection{Mechanically Induced Phase Transformation}

The stress-strain curves are shown in Fig.10. Samples were loaded at a constant temperature (50 degrees Celsius) above $A_{\mathrm{f}}$ until austenite fully converts to detwinned martensite (a steep gradient appears after a stress plateau). The samples fully recovered after unloading to zero stress.

The as-received sample hardly exhibits superelasticity. From the stress-strain curve it can be observed that the Young's modulus of as-received material is similar to the Young's modulus of austenite of aged samples, though it hardly transforms to martensite even at high stress level. Less 
stress hysteresis (at maximum around 100MPa) happens during loading/unloading process compared with those of other samples (over $300 \mathrm{MPa}$ ), which means that small-scale phase transformation still exists in as-received sample during loading. In addition, as-received $\mathrm{NiTi}$ alloy has much higher ultimate tensile strength (up to $1200 \mathrm{MPa}$ ) than aged ones, which corresponds with results from previous study [9].

Ageing treatment exerts a huge influence on superelasticity of NiTi alloy even in a short duration. As can be observed from the curve of 10 minutes' ageing sample, NiTi alloy exhibits an immediate increase in ductility and decrease in strength after ageing treatment. With the prolonging of ageing time, mechanical properties seem to continuously "retreat". In the first instance, the upper plateau strain of the sample with 10 minutes' ageing treatment was nearly $6.3 \%$, then this value gradually decreases to about $3.5 \%$ for the sample with 5 hours' ageing treatment. In the second instance, upper plateau stress for the sample with 10 minutes' ageing was nearly $600 \mathrm{MPa}$, while this value dropped to $450 \mathrm{MPa}$ for the sample with 5 hours' ageing. As is described in the mathematical model above, the volume fraction of $\mathrm{Ni}_{4} \mathrm{Ti}_{3}$ precipitate rises with ageing process. Previous researches have demonstrated that the improvement in superelastic performance after ageing treatment is mainly due to the change in internal stress state caused by $\mathrm{Ni}_{4} \mathrm{Ti}_{3}$ precipitate, to be more precise residual stress induced by $\mathrm{Ni}_{4} \mathrm{Ti}_{3}$ precipitate promotes phase transformation under applied stress. However, the volume fraction of precipitate increase leads to the reduction in volume fraction of transformable part of the material, namely austenitic parent phase. Therefore, the NiTi alloy may exhibit weaker superelastic behavior after longer ageing time.

A novel observation of present experiment result is the "trigger mechanism" before NiTi alloy turned from partially detwinned to fully detwinned, and vice versa. Stress-strain curves of aged samples exhibit two "sharp valley" regions. One appears after upper stress plateau during loading and the other appears before lower stress plateau during unloading. Rarely do previous researches report and probe the existence of these behaviors, but it's quite clear that the conversion between partially and fully detwinned martensite is not smooth-----there is a transition process between these two states and this process breaks the internal equilibrium of the material, which causes obvious fluctuation in stress level. The underlying reason for these dips is not clear, while our assumption is that it is due to the intrinsic characteristic of detwinned martensite microstructure.

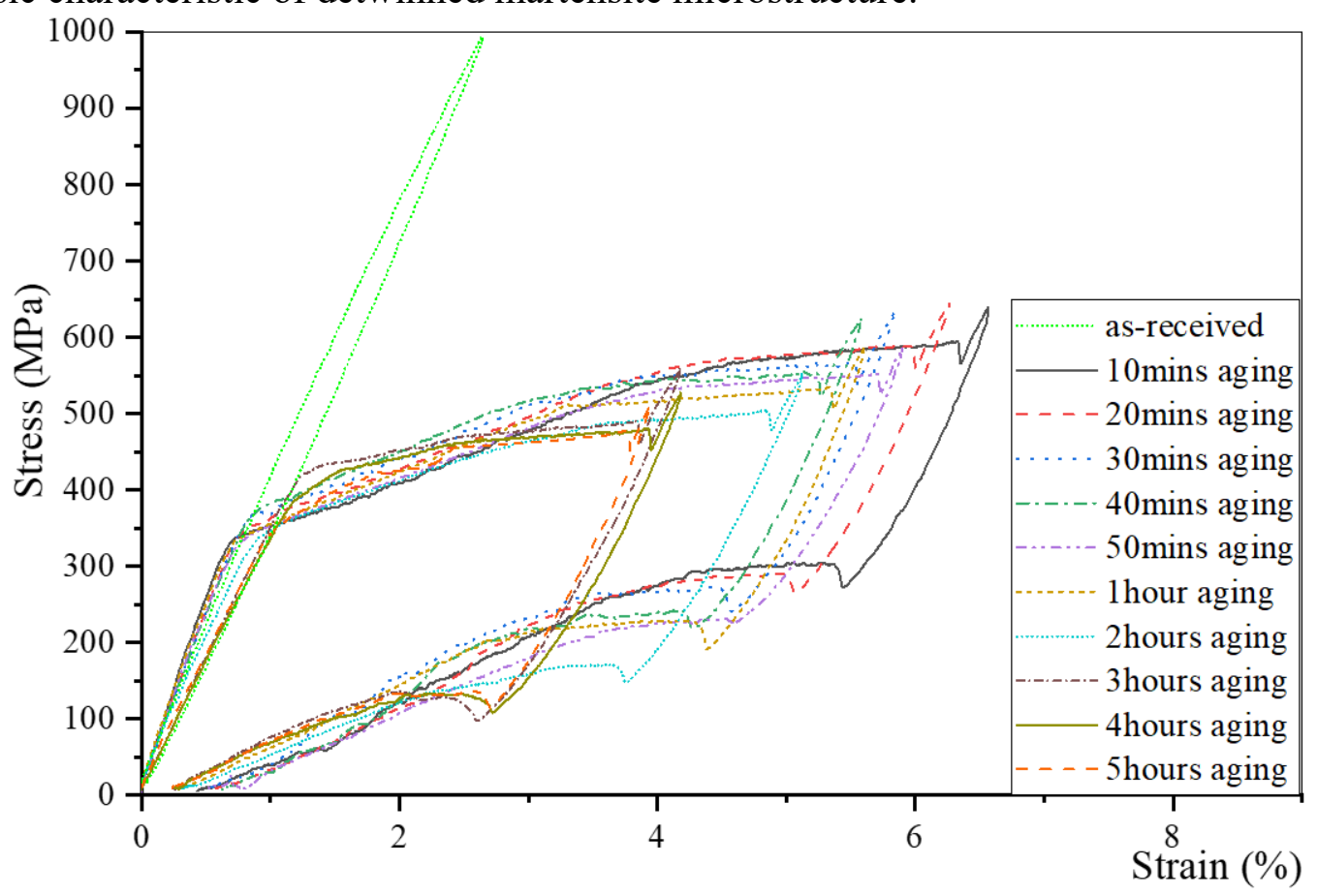

Figure.10 Isothemal stress-strain curves of samples at 323K

Salient stresses and strains in loading/unloading path of typical shape memory alloy are defined in Fig.11. $\sigma_{M}$ is the stress at which the samples begin to transform from austenite to detwinned 
martensite, $\sigma_{U P}$ is the maximum (upper) plateau stress and $\sigma_{\mathrm{LP}}$ is the maximum value of lower stress plateau. These critical points underlie the superelasic behavior of NiTi shape memory alloy.

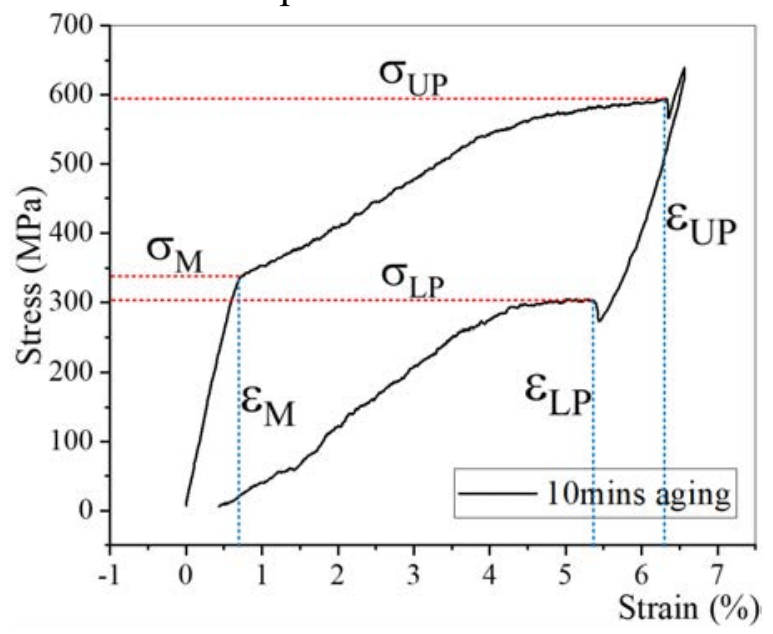

Figure.11 Definition of salient stresses and strains, i.e. martensite transformation stress $\left(\sigma_{M}\right)$ and strain $\left(\varepsilon_{\mathrm{M}}\right)$, upper plateau stress $\left(\sigma_{\mathrm{UP}}\right)$ and strain $\left(\varepsilon_{\mathrm{UP}}\right)$, lower plateau stress $\left(\sigma_{\mathrm{LP}}\right)$ and strain $\left(\varepsilon_{\mathrm{LP}}\right)$, in a loading/unloading cycle of NiTi alloy.

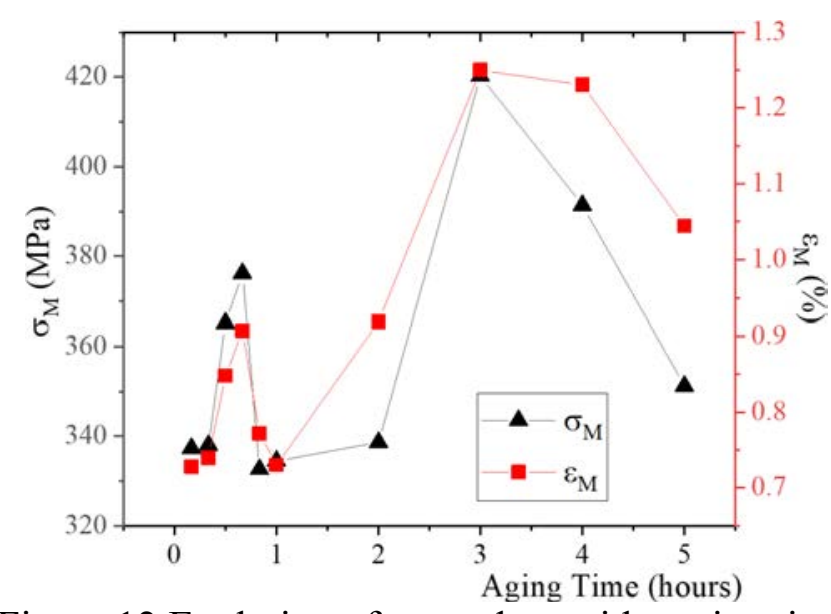

Figure.12 Evolution of $\sigma_{M}$ and $\varepsilon_{M}$ with ageing time

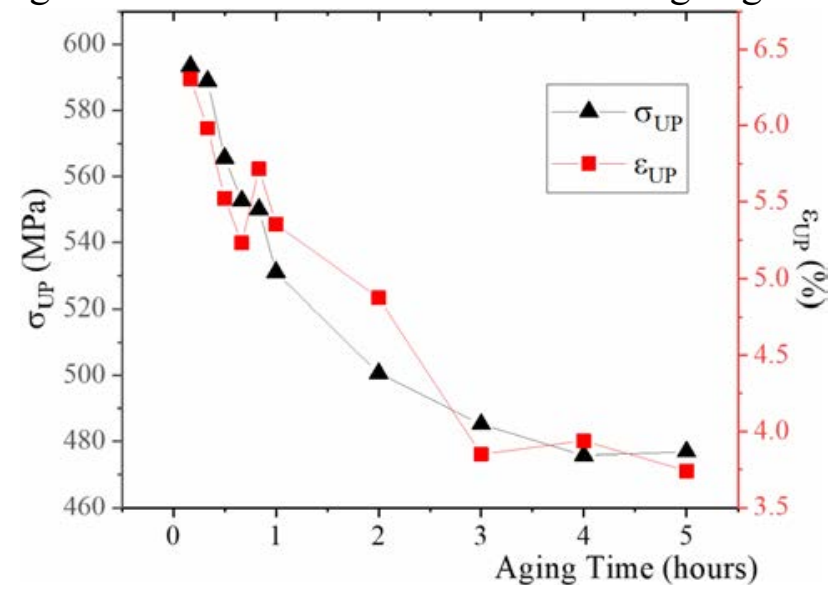

Figure.13 Evolution of $\sigma_{U P}$ and $\varepsilon_{U P}$ with ageing time 


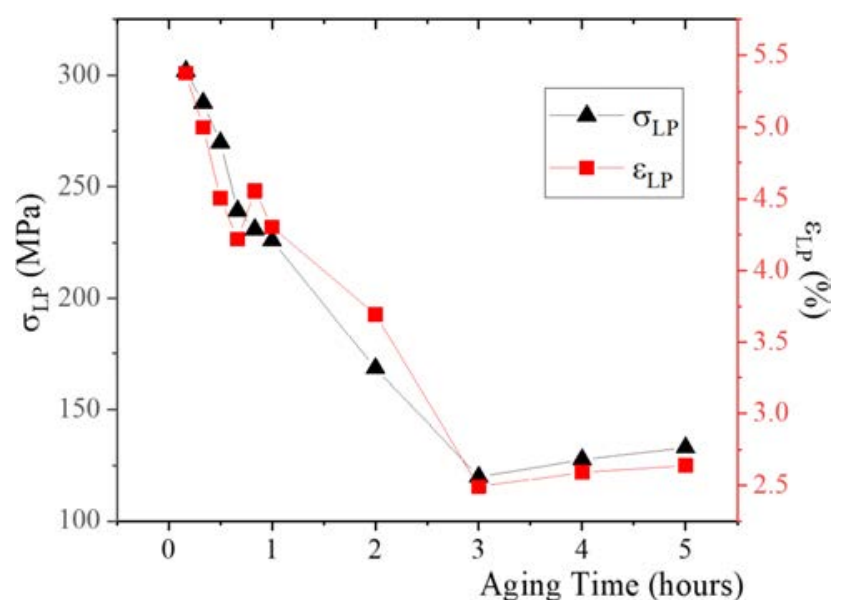

Figure.14 Evolution of $\sigma_{L P}$ and $\varepsilon_{L P}$ with ageing time

The effect of ageing treatment on salient stresses and strains is outlined in Fig.12, Fig.13 and Fig.14. Prolonging ageing time is responsible for the evolution of superelastic behavior. In the first three hours' heat treatment, samples exhibit rapid decrease in UP and LP stresses and the continuous fluctuation of $\sigma_{\mathrm{M}}$.

Two peaks can be observed in the evolution of $\sigma_{M}$ and $\varepsilon_{M}$, which is similar to the effect of ageing treatment on tensile strength of Aluminum alloys. Two microscopic processes take place simultaneously during ageing treatment of NiTi alloys. Firstly, the formation of precipitates induces local residual stress, which promotes the transformation from austenite to detwinned martensite at the beginning. With the prolonging ageing treatment, residual stress may be relaxed by atomic motion. This effect leads to the left small peak in Fig.12. Secondly, defects/dislocations in austenite phase are pinned by the embedding of $\mathrm{Ni}_{4} \mathrm{Ti}_{3}$ precipitate. As the precipitate grows, its effect on preventing dislocation motion is strengthened and then weakened due to the expanding size, which corresponds to the right peak. Therefore, competition between these two mechanisms leads to the undulation of $\sigma_{M}$ and $\varepsilon_{M}$. It can be concluded that $\sigma_{M}$ and $\varepsilon_{M}$ are sensitive to microstructure changes.

The sharp decline in UP and LP stresses results from the increasing $A_{\mathrm{f}}$ due to precipitation. As $A_{\mathrm{f}}$ increases the stress required to drive full martensite transformation is reduced. It is noteworthy that UP and LP strains share the same trends as stress values, decreasing rapidly in the first three hours and reaching a platform stage. The evolution of $\left(\sigma_{U P}, \varepsilon_{U P}, \sigma_{L P}, \varepsilon_{L P}\right)$ can be assumed to obey the mathematical form of Rule of mixtures and is associated with the volume ratio of $\mathrm{Ni}_{4} \mathrm{Ti}_{3}$ precipitate. The expression can be written as:

$$
\left(\sigma_{\mathrm{UP}}, \varepsilon_{\mathrm{UP}}, \sigma_{\mathrm{LP}}, \varepsilon_{\mathrm{LP}}\right)=f^{\prime} \cdot a_{1}+(1-f) \cdot a_{2}
$$

where $f^{\prime}$ is the volume fraction of parent austenite phase, which can be assumed to be $1 . f$ is the volume ratio of precipitate, expression of which refers to Eq.(4). $a_{1}$ and $a_{2}$ are parameters that have the same units as the left side of the equation. The definition of characteristic time $t_{\mathrm{c}}$ is also applicable to describe the evolution of ( $\left.\sigma_{\mathrm{UP}}, \varepsilon_{\mathrm{UP}}, \sigma_{\mathrm{LP}}, \varepsilon_{\mathrm{LP}}\right)$. It can be concluded that these properties are not sensitive to microstructure changes.

\section{Conclusion}

The present work is consisted of three main sections, namely EBSD/BSE evaluation of grain growth and precipitate formation after ageing treatment, modelling of critical temperatures in thermally induced phase transformation and analysis of salient stresses and strains in mechanically induced phase transformation.

For various aging durations at $773 \mathrm{~K}$, the dominant microstructural change in NiTi alloy is the formation and expansion of $\mathrm{Ni}_{4} \mathrm{Ti}_{3}$ precipitate, while the change in the martensite/austenite phase volume fraction and grain growth can be neglected.

Critical phase transformation temperatures show exponential decreases with increase of ageing time. A model based on thermodynamics is proposed by combining JMA equation and Arrhenius 
equation to predict the values of critical temperatures as a function of ageing time. Fitting results show that the model well matches the evolution of critical phase transformation temperatures and can be used as a reference to determine suitable ageing durations for NiTi shape memory alloys. Concept of characteristic time is also put forward, which is applicable to describe the evolution of all critical temperatures.

Ageing duration exerts a huge influence on salient stresses and strains. The stress and strain values ( $\left.\sigma_{U P}, \varepsilon_{U P}, \sigma_{L P}, \varepsilon_{L P}\right)$ drop steeply before reaching a platform. The $\sigma_{M}$ and $\varepsilon_{M}$ values exhibit two peaks due to the competition between evolution of residual stress and strengthening effect of precipitates. Further study is required to provide more insight into modelling these behaviors.

\section{References}

[1] J.M. Jani, M. Leary, A. Subic, M.A. Gibson, A review of shape memory alloy research, applications and opportunities, Materials and Design 56 (2014) 1078-1113.

[2] T. Daniels, Thermal Analysis, Halsted Press, London, 1973, pp.103.

[3] D.C. Lagoudas, Shape Memory Alloys Modeling and Engineering Applications, Springer Science+Business Media, LLC, New York, 2008, pp.71-95.

[4] X. Huang, Y. Liu, Effect of annealing on the transformation behavior and superelasticity of NiTi shape memory alloy, Scripta Materialia 45 (2001) 153-160.

[5] A.K. Srivastava, D. Schryvers, J.V. Humbeeck, Grain growth and precipitation in an annealed cold-rolled NiTi alloy, Intermetallics 12 (2007) 1538-1547

[6] K. Otsuka, X. Ren, Physical metallurgy of Ti-Ni-based shape memory alloys, Progress in Materials Science 50 (2005) 511-678.

[7] M. Carl, B. Zhang, M.L. Young, Texture and Strain Measurements from Bending of NiTi Shape Memory Alloy Wires, Shap. Mem. Superelasticity 2 (2016) 254-263.

[8] M. Losertova, M. Stencek, D. Matysek, O. Stefek, J. Drapala, Microstructure evolution of heat treated NiTi alloys, Conf. Series: Materials Science and Engineering 266 (2017) 012008.

[9] M.J. Drexel, G.S. Selvaduray, A.R. Pelton, The effects of cold work and heat treatment on the properties of Nitinol wire, International Conference on Shape Memory and Superslastic Technologies (2006) 447-454.

[10] D.Xue, Y. Zhou, X. Ren, The effect of ageing on the B2-R transformation behaviors in Ti51at\%Ni alloy, Intermetallics 19 (2011) 1752-1758.

[11] X. Yan, J.V. Humbeeck, Effect of annealing on strain-temperature response under constant tensile stress in cold-worked NiTi thin wire, Smart Materials Research (2011) Article ID 160927.

[12] J.K. Allafi, A. Dlouhy, G. Eggeler, Ni4Ti3-precipitation during ageing of NiTi shape memory alloys and its influence on martensitic phase transformations, Acta Materialia 50 (2002) 4255-4274.

[13] O. Bojda, G. Eggeeler, A. Dlouhy, Precipitation of Ni4Ti3-variants in a polycrystalline Ni-rich NiTi shape memory alloy, Scripta Materialia 53 (2005) 99-104.

[14] S. Jiang, Y. Zhang, L. Zhao, Y. Zheng, Influence of annealing on NiTi shape memory alloy subjected to severe plastic deformation, Intermetallics 32 (2013) 344-351.

[15] L. Neelakantan, A.W. Hassel, Rotating disc electrode study of the electropolishing mechanism of NiTi in methanolic sulfuric acid, Eletrochimica Acta 53 (2007) 915-919.

[16] A.K. Srivastava, D. Schryvers, J.V. Humbeeck, Grain growth and precipitation in an annealed cold-rolled $\mathrm{Ni}_{50.2} \mathrm{Ti}_{49.8}$ alloy, Intermetallics 15 (2007) 1538-1547. 
[17] M. Nishida, C.M. Wayman, T. Honma, Metal Trans 17A (1986) 1505.

[18] M.E. Mitwally, M. Farag, Effect of cold work and annealing on the structure and characteristics of NiTi alloy, Materials Science and Engineering A 519 (2009) 155-166.

[19] L. Jordan, M. Chandrasekaran, M.M. Masse, G. Bouquet, Study of the phase transformation in Ni-Ti based shape memory alloys, Journal de Physique IV Colloque 05 (1995) C2-489-C2-494.

[20] W.A. Johnson, R.F. Mehl, Reaction kinetics in processes of nucleation and growth, Tran. AIME 135 (1939) 416-458

[21] M. Avrami, Granulation, phase change and microstructure kinetics of phase change, III, J. Chem. Phys. 9 (2) (1941) 177-184.

[22] H. Li, K. Gai, L. He, C. Zhang, H. Cui, M. Li, Non-isothermal phase-transformation kinetics model for evaluating the austenization of 55CrMo steel based on Johnson-Mehl-Avrami equation, Materials and Design 92 (2016) 731-741.

[23] J. Bernardini, C. Lexcellent, L. Daroczi, D.L. Beke, Ni diffusion in near-equiatomic Ni-Ti and Ni-Ti(-Cu) alloys, Philosophical Magazine 83 (2003) 329-338.

[24] M. Kato, H-R. Pak, Thermodynamics of Stress-Induced First-Order Phase Transformations in Solids, Phys. Stat. Sol. (b) 123 (1984) 415-423.

[25] P.G. McCormick, Y. Liu, Thermodynamic analysis of the martensitic transformation in NiTi-II. Effect of transformation cycling, Acta metall. Mater. 42 (1994) 2407-2413.

[26] A. Planes, J. Ortin, Study of thermoelastic growth during martensitic transformations, Journal of Applied Physics 71 (1992) 950-957.

[27] L. Bataillard, J.E. Bidaux, R. Gotthard, Interaction between microstructure and multiple-step transformation in binary NiTi alloys using in-situ transmission electron microscopy observations, Philosophical Magazine A 78 (1998) 327-344.

[28] N. Zhou, C. Shen, M.F.-X. Wagner, G. Eggeler, M.J. Mills, Y. Wang, Effect of Ni4Ti3 precipitation on martensitic transformation in Ti-Ni, Acta Materialia 58 (2010) 6685-6694.

[29] J. Frenzel, E.P. George, A. Dlouhy, Ch. Somsen, M.F.-X. Wagner, G. Eggeler, Influence of Ni on martensitic phase transformations in NiTi shape memory alloys, Acta Materialia 58 (2010) 34443458.

[30] W. Tang, B. Sundman, R. Sandstorm, C. Qiu, New modelling of the B2 phase and its associated martensitic transformation in the Ti-Ni system, Acta Mater. 47 (1999) 3457-3468. 